\title{
Solar e-Cooking: A Proposition for Solar Home System Integrated Clean Cooking
}

\author{
Simon Batchelor ${ }^{1}$, Md. Arifur Rahman Talukder ${ }^{2}$, Md. Raihan Uddin ${ }^{2}$, Sandip Kumar Mondal ${ }^{2}$, \\ Shemim Islam ${ }^{2}$, Rezwanul Karim Redoy ${ }^{2}$, Rebecca Hanlin ${ }^{3}$ and M. Rezwan Khan ${ }^{2, *}$ \\ 1 Gamos Limited, Reading RG1 4LS, UK; simon@gamos.org \\ 2 Department of EEE, United International University, Dhaka 1212, Bangladesh; \\ arif.talukder@practicalaction.org.bd (M.A.R.T.); raihan.eee1@gmail.com (M.R.U.); \\ sandip.mf.007@gmail.com (S.K.M.); rumkii34@gmail.com (S.I.); rezwankarim60@yahoo.com (R.K.R.) \\ 3 African Centre for Technology Studies, Nairobi 00100, Kenya; r.hanlin@acts-net.org \\ * Correspondence: rezwanm@uiu.ac.bd; Tel.: +880-1716048946
}

Received: 23 August 2018; Accepted: 18 September 2018; Published: 27 October 2018

check for updates

\begin{abstract}
This paper presents the feasibility of using solar photovoltaics (Solar PV) as the energy source for cooking with special focus on the loss mechanisms and possible remedial measures. If the heat loss is minimized, to reduce the temperature losses, it is possible to cook with a low power source less than $500 \mathrm{~W}$. A slogan has been adopted by the researchers-'It is temperature that cooks food not heat', meaning that it is not the flow of energy that cooks food, but rather, that food is cooked when held at a key temperature for a time. The slogan draws attention to the core concept that if heat loss is minimized, maintaining the temperature inside the cooker and the cooking pan, then the cooking process becomes very energy efficient. The paper considers ways to maintain temperature, but with due reference to the 'art of cooking', those all-important cultural processes that determine how meals are made. A prototype solar home system e-cooker was designed, fabricated and tested for cooking different foods in Bangladesh. Experimental results are presented to show that cooking is possible using much less power and energy than is commonly thought. A cost analysis is also presented to show that such a cooker can be cost effective in off-grid areas if connected to a properly designed Solar Home System.
\end{abstract}

Keywords: clean cooking; solar e-cooker; Solar Home System; science and art of cooking; energy loss in cooking

\section{Introduction}

The main objective of this paper is to study the feasibility of using solar photovoltaic panels (solar PV) for cooking in off-grid rural areas (which is becoming known as e-cooking, or e-Cook). The design that is proposed is equally adaptable to the grid connected areas, but the main interest of this study is to look at its feasibility in the off-grid areas. A particular characteristic of off grid areas is that people are relatively poor, spend a significant share of their income to buy cooking fuel, and above all, face health risks associated with their traditional cooking practices, particularly for the women and children. The key challenges that determine the design of a solar PV based cooking for the off-grid areas is the cost of energy and reliability.

A simple technical design has been proposed that incorporates the preventive measure of heat loss to make the cooker energy-efficient, this being the single most important factor of the study to reduce energy cost. The study also considers the feasibility of incorporating a storage battery for enhanced reliability under poor sunshine conditions and the corresponding enhancement in the energy cost. 


\section{Background}

Cooking is an essential requirement for any community, irrespective of its geographical location or cultural heritage. While food preparation and cooking processes have cultural and geographical variation, the primary need for almost all cooking is energy in the form of heat. The heat can be used either directly by burning biomass, bio gas or fossil fuel, or by using electricity to generate heat. Even today, almost half of the world population depends on biomass and coal for their cooking [1,2], and Bangladesh is no exception [3]. Although in such areas the cost of cooking is not a major issue in the developed world, the picture is quite different in developing or under-developed countries. In such cases the cost of cooking the basic foods can exceed USD 10 per month and forms a significant part of the household budget [4,5].

Given its importance to the lives of the poor, it is interesting to note that despite the wide usage of cooking utensils in almost every household worldwide, the efficiency of cooking stoves and cooking processes is very poor. An alarming consequence of cooking with biomass in most of the developing or under developed world, is the emission of carbon particles or harmful gases [6,7]. This has led to a body of work that has sought to improve the combustion efficiencies of biomass, which has resulted in many forms of 'improved cookstoves' (ICS). Design of efficient cook stoves still dominates the sector and researchers are still suggesting different stove designs with varying degrees of efficiency. So far as global warming is concerned, emission from cooking is still a significant source $[2,8]$ and any reduction in emission from cooking can make a difference. However, recent studies have shown that only the best improved biomass cookstoves begin to reduce the emissions significantly, and even then, the associated health benefits may still be limited [9-11]. There has also been considerable debate as to whether the focus on Biomass ICS has been the best approach, noting that the uptake of improved cookstoves has barely kept up with population growth leading some to conclude that "The 'business-as-usual' scenario for the sector is encouraging but will fall far short of potential" [12]. This 'business-as-usual' scenario will still leave over one-half (57\%) of the developing world's population without access to clean cooking in 2020, and 38\% without even minimally improved cooking solutions.

The challenges faced by biomass cooking are virtually absent when people use gas or electricity for cooking. Where the resources are available and affordable, it is an increasingly common picture all over the world that people tend to switch to gas or electricity-based cooking. However, this does depend on the key caveats of 'available' and 'affordable'. In remote areas where grid electricity has not reached, biomass-based cooking dominates due to the difficulty in maintaining a supply of gas cylinders or other forms of fossil fuels and to keep the cooking cost within the affordable range.

Although in some countries and in some areas, even if the grid was available, cooking on electricity would cost more than collecting locally available biomass (The true cost of collecting firewood should include the time taken to collect, prepare and light stoves, and the cost to the health of the cook. This particularly affects women and children. When these full costs are included electricity is almost always 'cost effective'. However, most households are not aware of these non-monetary costs.). In remote or rural areas, where access to electricity is very limited, the idea of cooking with electricity may not look attractive to households. However, the dynamics of energy provision are changing and energy technology is evolving.

In recent years, the reduced cost of solar photovoltaics (PV) has greatly increased the rate of penetration of PV-based electricity supply in remote and off-grid areas, particularly in the form of solar home systems (SHS) [13,14]. This has mainly been used for lighting, charging mobile phones and in some cases, radio and television $[15,16]$. These low power appliances have been chosen to keep the cost of solar home systems affordable, and until recently, few in the development sector would have considered using SHS for cooking. Whenever the issue of cooking using solar PV in the remote areas is raised, the main concern is whether the amount of power or energy needed for cooking can be supplied by solar PV at an acceptable cost.

The feasibility of solar e-cooking can be viewed from three different angles: first is the technical feasibility and the second is the economic viability. Technically, availability of required power is the 
key criterion when sizing the system for electric cooking. In case of solar PV based cooking, reliability is an associated issue, because sunshine is available during the day time only and varies with the weather conditions. So, access to energy storage, such as a battery, can enhance the system. On the other hand, economic feasibility needs to look at the cost of the design, cost of the energy and cost of maintenance. A third issue, as a result, is also the convenience of use.

All these three issues are addressed in this paper, with particular focus on solar home systems, as all the solar home systems have solar PV as the energy source and battery as the backup to address the reliability issue. Although the findings will equally encourage the grid connected users to utilize e-cooking, the work is focused on the less advantaged off-grid rural people where access to other forms of energy such as gas cylinders is limited. Considering this, the present or future owners of solar home systems may find it very attractive, both technically and economically, to cook using solar PV. The basic need for the success of such a proposition lies in lowering the cost, as well as the cost of energy as the single most important component. Hence, the lowering of the cost is closely related to the minimization of heat loss.

This paper, while considering the art and science of cooking, presents the design of low powered electric cooking stoves that can be powered by PV at a reasonable cost [17].

\section{Science and Art of Cooking}

When one speaks of the 'science of cooking', one focuses on how much power is needed to be supplied corresponding to the cooking processes, and what is the total energy consumption. Hence the literature involved in Solar Home Systems typically tends to focus on which appliances can be used by considering their power rating and their total energy consumption [14,15]. Traditionally, electric hotplates are rated at a kilowatt or more, leading to the usual notion that this is 'too high a power to be put on a solar PV based system' due to the small size of the solar panels and the cost of energy. The literature also shows that the average daily energy consumption of households (family of five) for cooking is of the order $2.2 \mathrm{kWh}$ [18], which would lead to large unaffordable systems. However, this paper will challenge both these points of view.

At the same time anyone considering innovative engineering responses must consider the 'art of cooking'. The taste and delicacy of cooking varies widely worldwide and so does the 'art of cooking'. Technically speaking, the 'art of cooking' involves different cooking processes such as frying, boiling, simmering, baking, grilling, etc. and all of them involve different temperature levels and different cooking environments. Any redesign of a cooking system needs to take into account, not just the power rating and energy consumption, but also, human preference for when cooking occurs, how much control to exercise on each process, when to stir, etc., so as to ensure the cook is happy with the final result.

To bring these thoughts together, strictly speaking, it is the temperature that needs to be maintained in most processes of cooking. Contrary to the usual notion that all depends on the power supplied, cooking is in fact done by maintaining the correct temperature. Once the process has reached its desired temperature, extra energy is only required to maintain that temperature-to offset the heat losses of the pan or oven. As researchers, the authors have adopted the slogan-'It is temperature that cooks food not heat'; this means that it is not the constant flow of energy that cooks food, but rather, that food is cooked when held at a key temperature for a time. In the section below the paper discusses the main heat loss mechanisms commonly found in cooking with electricity, but before doing that, focuses on air flow. Electricity has a major advantage over any other fuel because it does not require air flow.

As stated above, the actual need for power in cooking and the total energy requirement can be reduced significantly if the heat loss from the stove can be reduced. However, in the case of both fossil fuels (gas and coal) and biomass (wood, charcoal, dung, ethanol) cooking appliances, there is a limit to the efficiency that can be achieved due to air flow. The process involves combustion, removal of combustion products in the form of exhaust and recharging of fresh air (oxygen) [19]. In case of 
biomass cookers, it is difficult to achieve more than $30 \%$ efficiency and the usual energy efficiency of conventional three stone stoves can be less than $10 \%[20,21]$.

The stoves using biomass or fossil fuel have the inherent limitations to energy efficiency as these stoves require fresh air with oxygen for the combustion process. The intake is cool fresh air from the atmosphere and the combustion product, that must leave the combustion chamber of the stove to make room for the incoming fresh air, is hot. It is very difficult to achieve a very high level of heat transfer from the hot exhaust containing carbon dioxide, which is the main mechanism of heat loss from the stove. One can enhance the efficiency of the biomass-based stoves by ensuring optimal air flow, extracting heat from the exhaust for additional usages and in some cases, preheating the incoming air. However, adoption of all these processes can make the design of the stoves complicated, and in some cases, expensive and non-workable in a kitchen environment.

This limitation in efficiency, caused by air flow, is also true, to some extent, in gas fired stoves. Boiling a pan of water on a conventional stove means that a considerable amount of energy is flowing up and around the pan, into the atmosphere. Controlling the gas supply to match the cooking process can be an important efficiency measure, but it is common for cooks to keep the gas supply high even when the pan is already boiling. Gas ovens tend to use the heat more effectively, circulating the air to extract the heat, and using automatic temperature controls to turn the gas up and down. Nevertheless, the ongoing need for air flow sets a limit to how efficient the whole process can be.

In case of electric cooking the cooking chamber can be made very well insulated and loss of heat can be reduced drastically, as no fresh air intake is needed. The typical efficiency of electric hotplates is $70 \%$ or less and their inefficiencies are discussed further below [22]. However, if one considers that air flow is not a constraining limitation, one can envisage how the efficiency can be raised to nearer $90 \%$.

\section{Identifying the Main Heat Loss Mechanisms}

Hot plates in electric cookers are commonly used in the developed countries where access to affordable electricity is wide spread. Figure 1 illustrates the common losses when bringing a pan up to temperature for cooking on a hotplate cooker. Losses are marked (A) to (E).

E) A lid is known to make a lot of difference to evaporation and steam losses, but there may be radiant losses

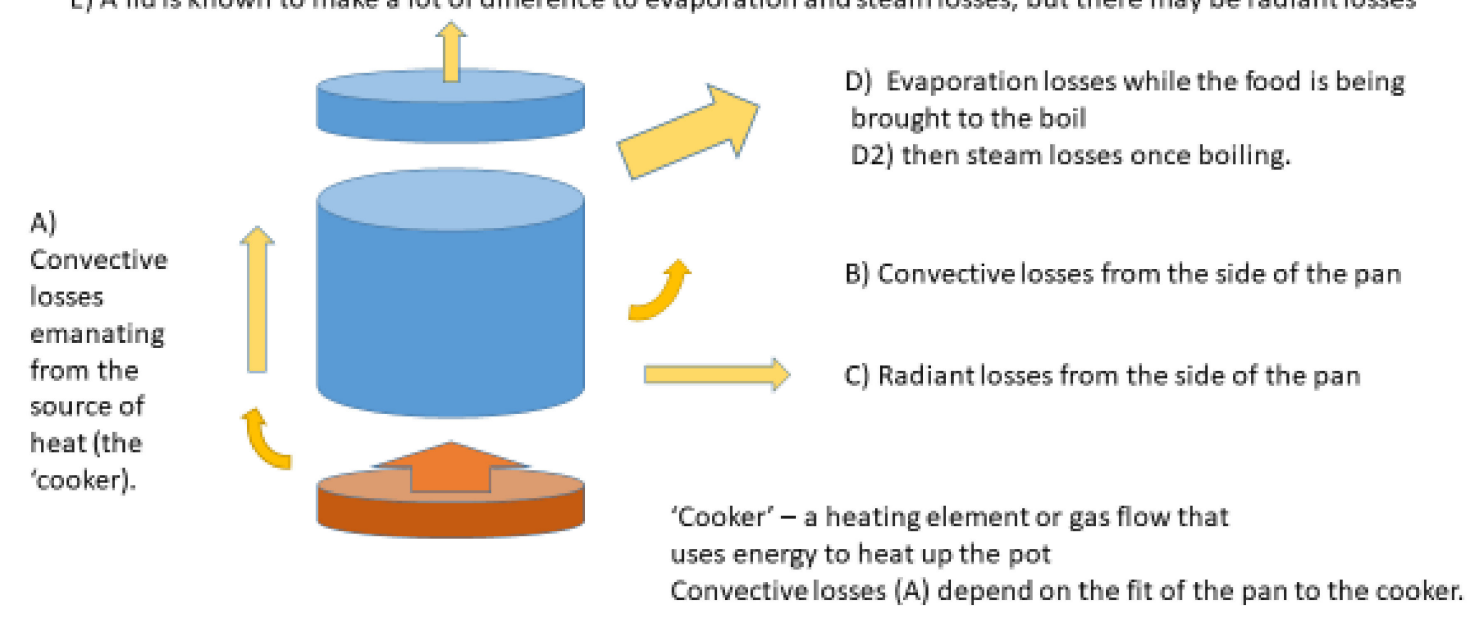

Figure 1. Schematic showing main heat losses from a pan during cooking.

The following paragraphs clarify the losses associated to the different concepts in the figure:

(A) Ill-fitting pans. If a pan is smaller than a hotplate, there is considerable loss of energy up the side of the pan through air convection. The warm air rises, 'missing' the pan. Given that electricity does not need air flow, this is a completely unnecessary loss. Good fitting pans are important. A similar effect can be found where the pan does not have a flat bottom and is only partially touching the hotplate. 
(B) and (C): Radiation, conduction and convection losses from the stove and the cooking pan. While cooking, it is a common observation that the body of the stove and the surface of the pan used for cooking become very hot, in most of the cases hot enough to cause burns and can scald the skin if touched. Such exposed surfaces lose heat due to radiation and convection. It is estimated that a moderate sized pan on a stove can lose approximately $120 \mathrm{~W}$ of power due to convection and radiation, if not insulated. It is possible to reduce these losses significantly if proper insulation is used on the pans and the stove surfaces.

(D) and (E): Loss of steam from the food in the cooking pan. Another significant energy loss is due to the escaping of steam from the cooking pan/pot. Each gram of steam that escapes the pan carries away more than 2200 joules of energy. Usually, the loss of heat due to escaping steam is highest during the final part of cooking. A lid is vital to reduce evaporation losses while the temperature increases and food is being brought to the boil. In the final stage, if heat continues to be added from the hotplate, the water in the pan boils more vigorously but the temperature does not increase. Although it is a common belief that a vigorous boiling of water means a faster cooking rate, the actual process of cooking is not quicker. The steam loss from the food can be reduced if the stove temperature can be controlled and kept close to $100^{\circ} \mathrm{C}$. Pressure cookers are the good examples where cooking efficiency is significantly higher as loss of steam is very low. Also, the high pressure raises the temperature of cooking that reduces the time required.

Post-cooking heat loss: In conventional cooking, cooks tend to take off the pans from the stoves after the food is cooked. Most people then leave the pans to cool down to get the right temperature suitable for eating. However, this action does not consider that cooking may still continue even after the cook takes the pan off the stove when the pan temperature is sustained. The 'Wonderbag', hotbox and 'fireless cookers' are products where heat conservation is used for slow cooking [23]. If done consciously, this can reduce the energy requirement by a significant margin.

Some of these losses are addressed by different appliances. In almost all hot plates, the temperature control is manual and the user sets a power level for the hot plates as per their needs. However, electric ovens or rice cookers have built in temperature sensors and the power supply to the device is adjusted automatically depending on the set temperature. Induction heating is increasing in popularity in cookers since only the pan is heated by electromagnetic induction and the heat is automatically transferred to the food in the pan. As it does not require any heating element, the heat insulation can be made more effective and the efficiency is higher than the usual cooking hot plates, more than $80 \%$ [24]. Microwave ovens are one step ahead of the induction heaters, in so far as the science of cooking is concerned, as they heat only the food inside an insulated container reducing the heat loss further.

The above is stated from the 'science of cooking' point of view. The 'art of cooking', sometimes disrupts the purity of energy retention. For instance, there are types of food preparation where people would like to stir the food continuously or keep the pan lid open. In such a case, the prevention of heat loss becomes ineffective. Addressing only the science of cooking will not be enough to devise an effective and efficient cooking solution.

\section{A Proposition for Solar e-Cooking: Feasibility and the Challenges}

Based on the concepts above, it has been concluded that the actual power requirement of a cookstove can be reduced significantly if the losses can be reduced. Reduction of losses would mean an innovative design of the stove and the pan. Adopting very effective insulation for both the stove and the pan is relatively simple in electric stoves as no fresh air intake is required.

Insulating the heating element. One can conceive of an electric stove where the stove heating element is insulated from the stove frame in such a way that transfer heat is only allowed to the bottom of the pan. A scan of the cheaper hotplates on the market shows that the base of the heating element is exposed, and there is considerable opportunity for losses from radiant heat with associated convective air flow from below the main element. 
Controlling the power. Control of power in an electric stove is relatively simple (compared to biomass stoves) and temperature sensors or a manual power control unit can control the power of the heating element as required. This will ensure that the heating element either reduces or cuts off-power consumption once the food inside the pan reaches the required temperature (for example, close to $100^{\circ} \mathrm{C}$ ) and reduce loss of steam from the boiling water in the pan.

Insulating the cooking container. At the same time, the side and the top of the pan can also be insulated to minimize heat loss from the pan while cooking.

To estimate the power requirement of such a stove let us assume that the average food to be cooked in the pan is equivalent to $1 \mathrm{~L}$ of water $(1 \mathrm{~kg})$. Assuming the room temperature to be $25^{\circ} \mathrm{C}$, the amount of heat required to raise the temperature to $100{ }^{\circ} \mathrm{C}$ is

$$
\mathrm{Q}=(100-25) \times \mathrm{S} \times \mathrm{W}=312,750 \mathrm{~J}
$$

where $\mathrm{S}$ is the specific heat of water $(4170 \mathrm{~J} / \mathrm{kg}$ ) and $\mathrm{W}$ is the amount of water in $\mathrm{kg}$ (in the calculation it is $1 \mathrm{~kg}$ ). Assuming that the power to be fed to the water is $P$ and the water temperature reaches $100{ }^{\circ} \mathrm{C}$ in $\mathrm{t}$ secs then heat balance can be written as

$$
\mathrm{Q}=\mathrm{P} \times \mathrm{t}=312,750 \mathrm{~J}=0.078 \mathrm{kWh}
$$

which makes

$$
P=260.6 \text { Watt }
$$

taking $\mathrm{t}=20 \mathrm{~min}=1200 \mathrm{~s}$.

The amount of power chosen can be higher or lower than that found in Equation (3). But it should not be too low so that the heat loss from the system becomes close to the amount of power given to the heating element. This will result in either stagnant temperature or the rate of rise of temperature becomes too slow increasing the cooking time to an unacceptable level. A high input of power does not necessarily mean that the cooker will have higher power loss, but it will definitely shorten the cooking time, which may be of advantage of the user. But a higher power could also mean extra cost, as the size of the panel and possibly the battery needs to be increased.

\section{Methodology-A Prototype Solar e-Cooker}

A schematic diagram in Figure 2 shows the basic structure of the prototype e-cooker. The resistive heating element is placed in a small stainless-steel pot at the center of the e-cooker structure. The steel pot conducts heat from the heating element and makes the heat distribution more uniform. At the same time, the heat that is radiated downward is reflected back to the pan and heat loss is reduced. The top and bottom of the stove is made from fiber glass sheet with glass wool placed in between. The electrical connection for the heating element is made through the glass wool shown in Figure $2 b$.

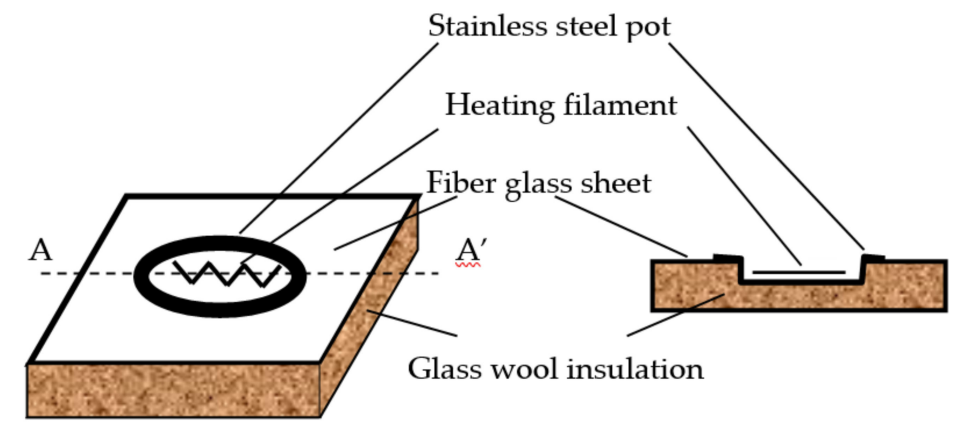

(a)

(b)

Figure 2. (a) Schematic diagram of an e-cooker; (b) cross sectional view at AA'. 
The primary criterion in designing the prototype was to keep the power consumption close to $300 \mathrm{~W}$. The power of the heating element is kept at such a low value that even small amounts of heat loss can disrupt the function of the design. As already discussed, designing the stove only with proper insulation is not enough to cook at such a low power. The initial design also included insulation for both the stove and the pan. The most challenging part of the design was choice of good quality insulation at an acceptable cost. After a number of trial and error, the workable stove, as shown in Figure 3 was developed. The total cost of the e-cooker was around USD 30 (without the pans). With mass production, the cost is expected to come down close to USD 15.

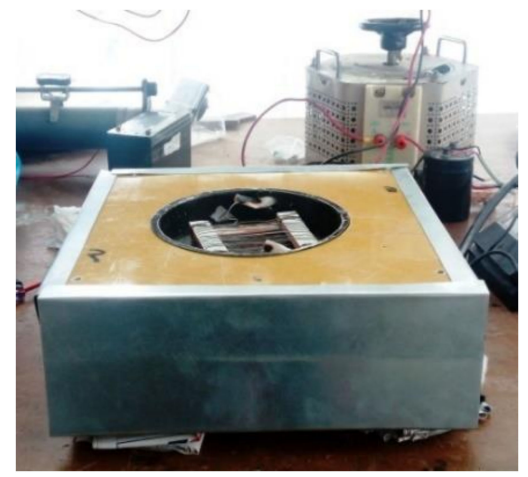

(a)

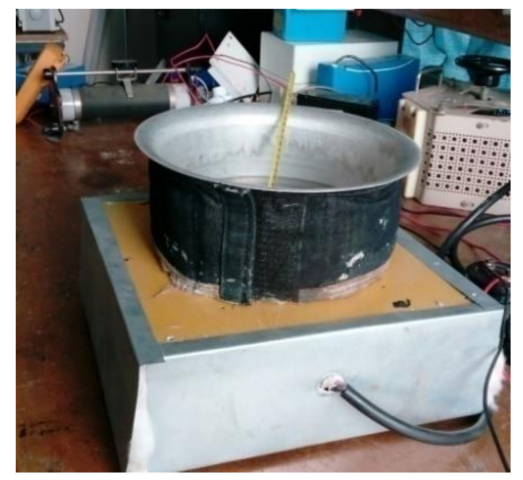

(b)

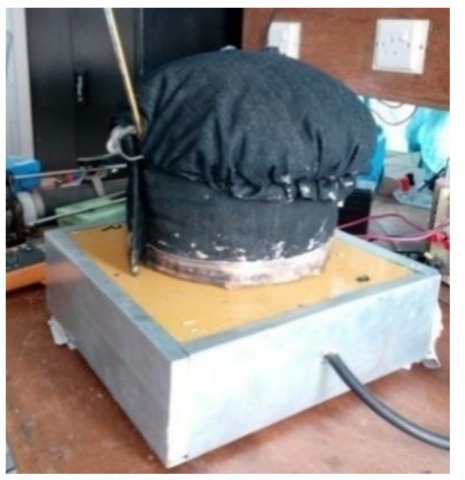

(c)

Figure 3. Photographs of the prototype e-cooker. (a) The e-cooker; (b) the electrical connection through the insulation and circumferential insulation cotton wool jacket; (c) cooking pan is covered with cotton wool jackets for insulation.

As shown in Figure 3, the pan is also insulated on all sides, including the lid, except for the bottom, to allow heat from the stove to the pan. Once the pan is taken off the stove, it is to be placed on an insulated base to preserve the heat inside the pan, as shown in Figure 4. This will ensure that additional cooking will take place even after the pan is placed on the insulated base, emulating but being easier than the Wonderbag; once again-it is temperature that cooks, not heat.

The insulation thickness in the stove and pan is determined empirically such that the temperatures on the surfaces do not exceed $50{ }^{\circ} \mathrm{C}$. This was necessary to make sure that the loss of heat is reasonably contained. It is possible to make the insulations even thicker to reduce the heat loss further, but that will increase the size of the stove and the pan, and at the same time, the cost.

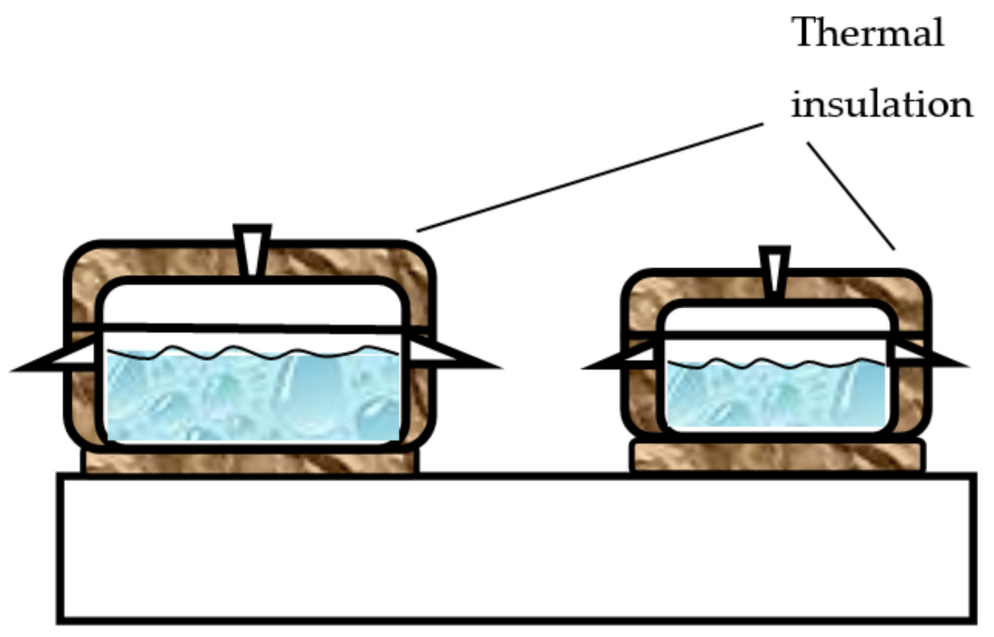

Figure 4. The insulated resting place for the pans after taking off from the stove. 
Given that the prototype is designed for use with Solar Home Systems, and potentially seeks to draw from batteries, the system was $48 \mathrm{~V}$ direct current.

\section{Methodology-Testing the Prototype Stove}

Water. An experiment was undertaken with $1 \mathrm{~L}$ of water placed in the pan and the heating element was energized with $297 \mathrm{~W}$. The time required to reach the boiling temperature of $100{ }^{\circ} \mathrm{C}$ from the room temperature of $25^{\circ} \mathrm{C}$ was $25 \mathrm{~min}$. In theory, without significant heat loss, estimated calculation suggested the time should be $20 \mathrm{~min}$ for a power of $260 \mathrm{~W}$. In practice, the longer time required was thought to be due to two reasons: first is the absorption of a portion of heat by the mass of the pan and the stove, and second is some unexpected heat loss from the insulated region. Nevertheless, the actual time needed to reach $100{ }^{\circ} \mathrm{C}$ is within acceptable parameters.

After repeat experiments with $1 \mathrm{~L}$, the experiments were conducted with $2 \mathrm{~L}$ of water, to gauge the assumption that the heat absorbed by the pan and the stove would remain the same as the temperature rise increases to $100^{\circ} \mathrm{C}$. This would give a better estimate of the field efficiency. The results are shown in Table 1. Applying a similar amount of power (297) to the heating element the boiling temperature was reached within $40 \mathrm{~min}$. There was very little variation across tests. The estimated efficiency was $86.5 \%$.

Table 1. Water boiling test.

\begin{tabular}{cc}
\hline & $\begin{array}{c}\text { Amount of Water: } \mathbf{2} \text { L } \\
\text { Pan Weight: 0.440 kg } \\
\text { Power Supplied: 297 Watts } \\
\text { Estimated Efficiency = 86.5\% }\end{array}$ \\
\hline Time in Minutes & Temperature in Degree Celsius \\
\hline 0.00 & 26 \\
5.00 & 37 \\
10.00 & 43 \\
15.00 & 52 \\
20.00 & 62 \\
25.00 & 72 \\
30.00 & 82 \\
35.00 & 92 \\
40.00 & 100 \\
\hline
\end{tabular}

Rice. To ensure that the outcome with food would be similar, after the boiling water experiment, $0.25 \mathrm{~kg}$ of rice in $0.5 \mathrm{~kg}$ of water was cooked (Table 2). Taking advantage of the insulated environment, the rice in water was raised to temperature and then taken off the stove. The cooking took about $35 \mathrm{~min}$, out of which $25 \mathrm{~min}$ was on the stove. Rest of the time the pan was placed on the insulated base. The rice was tested for taste by researchers. Again, there was little notable variation in test results across repeated tests.

Table 2. Rice boiling test.

\begin{tabular}{cc}
\hline \multicolumn{2}{c}{$\begin{array}{c}\text { Amount of Rice: } \mathbf{0 . 2 5 0} \mathbf{~ k g} \\
\text { Amount of Water: } \mathbf{0 . 5} \text { L; Pan Weight: } \\
\text { Power Supplied: } \\
\text { Po1.3 Watt }\end{array}$} \\
\hline Time in Minute & Temperature in Degree Celsius \\
\hline 0.00 & 26 \\
5.00 & 38 \\
10.00 & 54 \\
15.00 & 72 \\
20.00 & 91 \\
22.00 & 100 \\
\hline
\end{tabular}


Beef Curry. In the progression towards real life cooking, a set of tests were conducted on beef curry using a pressure cooker. The surface temperature of the pressure cooker inside the insulation was measured. The cooking materials inside the pressure cooker are given below as a part of Figure 5 .

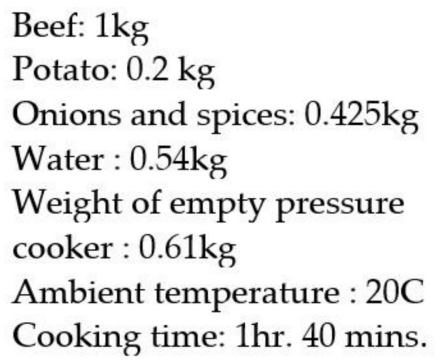

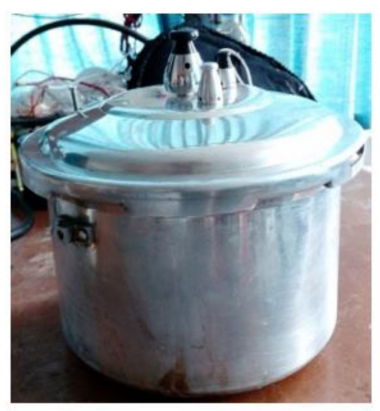

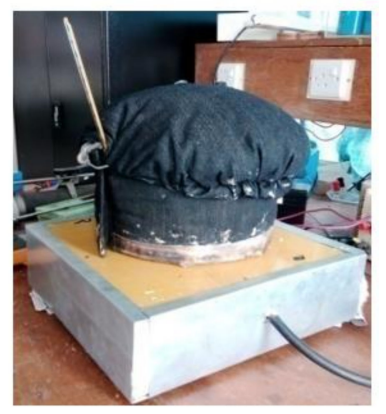

Figure 5. Experimental setup for e-cooking using pressure cooker.

The pressure cooker was heated for $1 \mathrm{~h} 15 \mathrm{~min}$ and then placed on the insulated based for another $25 \mathrm{~min}$ before the curry was checked. The outside temperature of the pressure cooker was $120^{\circ} \mathrm{C}$ when it was taken off from the e-stove. After a total time of $1 \mathrm{~h} 40 \mathrm{~min}$, the lid was opened and the beef was found to be well cooked.

Fried Potato. As it is well understood that changes in cooking habit by the users are difficult to achieve, an attempt was made to fry potato in the e-cooker with minor deviation from the usual frying procedures. The sides of the frying pan were insulated with a cotton wool jacket and a glass lid (glass is a reasonably good insulator) was used instead of the conventional metallic lids. A total of $380 \mathrm{gm}$ of potato chips were fried and it took around $28 \mathrm{~min}$. The frying-pan for fried potato curry is shown in Figure 6.

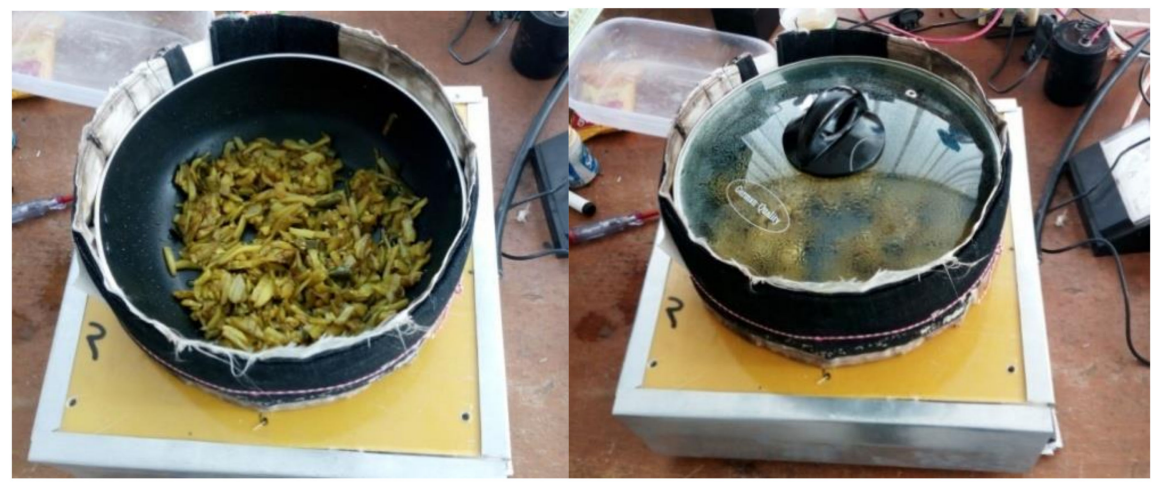

Figure 6. Arrangement for the potato chip frying in the e-cooker.

\section{Results and Discussion}

Using our prototype solar e-cooker, it is clear that cooking is possible using lower power heating elements as low as $300 \mathrm{~W}$. Some of the food, such as beef, can take a long time to cook even using a pressure cooker; however, energy input is not required for the whole time.

Raising the temperature. Due to low energy heating element it takes significant time to raise the food temperature from room temperature to the required cooking temperature (such as $120^{\circ} \mathrm{C}$ in the pressure cooker experiment). The temperature of $300 \mathrm{~W}$ was chosen as a target for a solar panel of that power rating, which would retrofit easily to most Solar Home Systems in Bangladesh. However, a higher heating element such as $500 \mathrm{~W}$ will shorten the cooking time, which would be of benefit to the users. Increasing the heat rating of the filament further may not be to the advantage of the user as people do parallel processing of other cooking preparations, while one of the dishes is being cooked. 
It is important to mention that, increasing the heat rating of the filament does not necessarily mean that the overall system size of Solar Home System will have to increase proportionately.

Retaining the energy. Higher rating of the heating element leads to less cooking time although it would likely keep the overall energy requirement approximately same. Consider the prototype to the rated power for rice cookers or hot plates (usually of the order of $1000 \mathrm{~W}$ or higher).The actual amount of energy needed for cooking is not very high if we can make sure that the heat supplied is transferred to the food in the pan, and only a small portion of it is lost.

Constant stirring usually means higher heat loss although qualitative field work suggests that there are few foods that need 'constant' stirring. Even under such requirements, it could be possible to conceive of a special lid with holes which would allow externally driven stirring-which of course is a principle of appliances such as dough makers (the dough making attachment of food processors). No doubt, such an arrangement will require extra power to drive the dough maker and the user will have to ensure that that power is available, or perhaps mechanical devices need to be incorporated without compromising the insulation. Even under such requirements, it should be possible.

Sizing the panel. Looking at the power requirements, the actual panel size will vary for different locations due to the variation in sunshine, but a panel size of $500 \mathrm{Wp}$ would be a reasonable choice as it is capable of producing close to $300 \mathrm{~W}$ even under moderate sunshine condition.

Reliability. However, it is important to keep in mind that sunshine can be very low on some specific days when there is heavy cloud or fog. An alternative arrangement, such as a battery backup, could be considered to keep the energy supply reliable. However, a battery backup will increase the system cost to a much higher level, such that the overall proposition of solar PV e-cooking may lose its attraction as a viable alternative to conventional cooking.

\section{Cost Analysis and Integration with Solar Home System}

Let us first make the cost calculation assuming that no battery backup is used. Previous attempts have been made to create 'solar cookers', i.e., using the direct sunshine to cook food [25-27]. The disadvantage of these has been that the cook has had to work in the sunshine, and to cook at certain times of the day. In our case, even without a battery, the system proposed has some thermal storage in the food itself, and the cook can utilize the cooking appliances inside a house. Therefore, even without a battery, the solar e-cooker system has considerable advantages over the experiences of conventional 'solar cookers'.

A $500 \mathrm{Wp}$ panel with its fitting and fixing expenses on the roof top, similar to a solar home system, will cost approximately USD 300 in Bangladesh. Assuming that one can extract a maximum of $80 \%$ of the power produced by the panel, then considering an interest rate of $10 \%$ (which is on the higher side even for the developing countries) and a life time of 20 years with a maintenance and operational cost of $5 \%$ per year, the cost comes out to be (using discounted cash flow):

$$
\mathrm{C}(\mathrm{PV})=300\left[0.1 /\left(1-(1+0.1)^{-20}\right)+0.05\right]=50.23 \mathrm{USD} / \text { year }
$$

The amount of energy produced by the panel for an average daily insolation of $4.5 \mathrm{kWh} / \mathrm{m}^{2}$ (insolation in Bangladesh) is $821.25 \times 0.8=657 \mathrm{kWh}$ and the cost of electricity comes out to be

$$
\mathrm{C}(\text { solar PV electricity })=50.23 / 657=0.0765 \mathrm{USD} / \mathrm{kWh} \text {. }
$$

The cost of electricity will vary with availability of sunshine and interest rate, but does not have significant variation with the size of the panel, unless the panel size is very small. Assuming that the average time of cooking is $4 \mathrm{~h}$ per day with an average delivered power of $300 \mathrm{~W}$, then the monthly cost of electricity for cooking comes out to be:

$$
\mathrm{C}(\text { cooking })=0.0765 \times 0.3 \times 4 \times 30=2.754 \mathrm{USD} / \mathrm{month}
$$


This is a very attractive cost figure so far as the existing cost of fuel for cooking is concerned.

\section{Energy Storage and Batteries}

However, the main challenge in a solar e-cooker is the reliability of sunshine. As cooking is an essential element in a household, its effectiveness will be greatly affected if there is no backup power with the solar panel to cater for the energy shortfall during cloudy or foggy days. At the existing market price of batteries, the cost per energy unit will increase significantly if a dedicated battery backup is used. There is, therefore, a balance point-reliability and optimum utilization has to be offset against affordability. The addition of a battery to the cooking system may make the system lose its attraction to the very poor due to enhanced energy cost.

On the other hand, the energy output of the solar panel may remain unutilized if the panel is dedicated for cooking only, as the cooking hours will not usually exceed $4-5 \mathrm{~h}$ per day. Under these circumstances, integrating cooking with a Solar Home System could be considered.

Solar Home Systems are quite popular throughout the off-grid rural areas in the developing world. Although very successful as a primary step towards energy access, the main criticism levelled against them is the low power output that cannot accommodate many of the household gadgets [28-31]. As a consequence, there is much discussion about the inclusion of economic activities beyond the capacity of a regular solar home system for lights [32,33]. The aim of including productive use in solar home systems has been to make the total system more cost-effective.

Moreover, if the solar e-cooking is integrated with a Solar Home System, the householder has the advantage of reliable cooking power at a marginal additional cost, utilizing the solar Home system including the battery and making the total system more cost effective. When integrated with Solar Home System, it may be possible to safely reduce the size of the panel to $300 \mathrm{Wp}$ and use the cost saving to increase the size of the battery. The table below gives some results to show that the energy cost when cooking is integrated with solar home system. Battery storage will cause an additional loss of $15 \%$ of the PV output that is included in the cost calculation. For higher sunshine conditions the cost would be even lower. At this stage the question may arise that once the solar home system is bought then the monthly installment for the system is independent of energy usage, so the question of cost saving does not arise. This question can be addressed by considering the fact that if the e-cooker is using a part of its energy during the sunshine hours in the day time, the size of the battery can be reduced. For the equipment, the monthly costs would be: $500 \mathrm{Wp}$ panel plus battery USD 9.42; $300 \mathrm{Wp}$ panel plus battery USD 7.74; while for the $500 \mathrm{Wp}$ panel alone USD 4.19. While calculating the energy cost, the life of the PV can be assumed to be 20 years, the life of tubular plate battery was 5 years. From Table 3, it is clear that cost of energy becomes almost 3 times when a backup battery is used. In many developing countries, people cook during sunshine hours and the cooking cost can be reduced significantly if cooking energy comes from the PV panel directly during the day time. As a test case, let us assume that $50 \%$ of the energy comes from the panel directly and the rest $50 \%$ comes from the battery (Table 3 ) then the cost figures at $4.5 \mathrm{kWh} / \mathrm{m}^{2}$ sunshine comes out to be

$$
\text { Cost of energy }=0.5(0.0765+0.202)=0.139 \mathrm{USD} / \mathrm{kWh}
$$

Based on this assumption power consumption of $300 \mathrm{~W}$ for the e-cooker with an average cooking time of $4 \mathrm{~h}$ per day

$$
\text { Cost of cooking }=0.139 \times 0.3 \times 4 \times 30=5.02 \mathrm{USD} / \text { month }
$$

which is smaller than the cost (USD 7.28) mentioned in Table 3. As the price of the PV and the battery is decreasing steadily, if we assume that there will be a fall in the price of the Solar Home System by $30 \%$ in next five years, the monthly cost will also reduce almost proportionately. 
Table 3. Cost of energy without and with battery backup when integrated with solar home system under different sunshine conditions. The cost is calculated assuming $4 \mathrm{~h}$ of cooking time per day.

\begin{tabular}{|c|c|c|c|c|c|}
\hline $\begin{array}{l}\text { Connected Load } \\
\text { (h/Day) }\end{array}$ & $\begin{array}{c}\text { PV System } \\
\text { Description (Cost) }\end{array}$ & $\begin{array}{c}\text { Avg. } \\
\text { Sunshine } \\
\text { kWh/sq.m }\end{array}$ & $\begin{array}{l}\text { Energy Cost USD/kWh } \\
\text { without Battery }\end{array}$ & $\begin{array}{c}\text { Energy Cost } \\
\text { with Battery, } \\
\text { USD/kWh }\end{array}$ & $\begin{array}{l}\text { Monthly Cost } \\
\text { for Cooking, } \\
\text { USD ( } 4 \text { h/Day) }\end{array}$ \\
\hline $\begin{array}{l}\text { Light } 12 \mathrm{~W},(4 \mathrm{~h}) ; \\
\text { Fan, } 12 \mathrm{~W},(6 \mathrm{~h}) ; \\
\text { TV, } 10 \mathrm{~W},(6 \mathrm{~h}) ; \\
\text { Refrigerator, } 50 \mathrm{~W},(6 \mathrm{~h}) ; \\
\text { e-cooker, }(4 \mathrm{~h})\end{array}$ & $\begin{array}{l}300 \mathrm{~W} \text { panel, USD } 180 \\
\text { including fitting and fixing; } \\
\text { Tubular plate Battery } 12 \mathrm{~V} \\
\text { (with charge controller), } \\
150 \mathrm{AH} \text {; USD 200; } \\
\text { Interest rate } 10 \%\end{array}$ & 4.5 & 0.0765 & 0.202 & 7.28 \\
\hline As above & As above & 5.0 & 0.0688 & 0.182 & 6.56 \\
\hline As above & As above & 5.5 & 0.063 & 0.166 & 5.96 \\
\hline
\end{tabular}

\section{Conclusions}

This paper addresses the main challenges of solar e-cooking-the energy cost and reliability. It is proposed that a cooker can be integrated with a solar home system to enhance the reliability with only additional marginal cost. Such a cooker can be used in the gridded areas as well, but as the focus of our study was on off-grid rural people who can significantly benefit from such a cooker.

This paper shows the importance of insulating the cooking pans for the sake of energy conservation, an important issue so far ignored. Although this is not a common practice, the authors believe that as electricity is used more for cooking, users will realize the importance of insulated pans in saving energy and perhaps as energy unit prices rise, pan manufacturers may even manufacture pans with proper insulation (such as putting a ceramic or glass layer on the outside). The energy cost for cooking with well insulated stoves and pans is so low that such stoves could have applications in both grid and off-grid areas.

The main technical challenge for this research was cooking food at such a low power within a reasonable time. The other challenge comes from the issue of change in cooking habits. Our experience indicates that there will be no need for change in habit while cooking rice, vegetable or meat, but frying can be more difficult.

The cost analysis indicates that integration of solar e-cooking with solar home systems by increasing the size of the PV panel and the battery can be quite cost effective when compared to usual cooking cost. At the same time, the increased power capacity of the solar home system will potentially enable the households to use more equipment such as fans for cooling, small refrigerators etc. potentially enhancing the quality of life of the users.

Author Contributions: S.B. initiated the idea, M.R.K. designed and performed the experiment, R.H. provided her feedback on the results and performance. Rest of the authors were research assistants involved in the fabrication and experiment.

Funding: The project was jointly funded by DFID and EPSRC, UK (ref: EP/L 022311/2). The collaboration partners are Gamos Ltd. UK, Africa Centre for Technology Study (ACTS), Kenya, LIGTT, UC Berkeley, CA, USA, United International University, Bangladesh and University of Sussex, UK.

Conflicts of Interest: The authors declare no conflicts of interest.

\section{References}

1. US Environment Protection Agency. 2015. Available online: https://www.epa.gov/air-research/cleancookstove-research (accessed on 29 May 2018).

2. WHO. 2018. Available online: http://www.who.int/airpollution/household/en/ (accessed on 29 May 2018).

3. Ministry of Power, Energy and Mineral Resources, Government of the People's Republic of Bangladesh. Country Action Plan for Clean Cookstoves. Available online: http:/ /www.sreda.gov.bd/d3pbs_uploads/ files/policy_5_cap_final.pdf (accessed on 29 May 2018).

4. Douglas Barnes and Keith Openshaw, Comparative Cooking Costs in Developing Countries, Energy for Development and Poverty Reduction. 25 April 2010. Available online: http:/ /www.energyfordevelopment. com/2010/04/comparative-cooking-cost.html\#more (accessed on 29 May 2018). 
5. Nerini, F.F.; Ray, C.; Boulkaid, Y. The cost of cooking a meal. The case of Nyeri County, Kenya. Environ. Res. Lett. 2017, 12, 065007. [CrossRef]

6. Anenberg, S.C.; Balakrishnan, K.; Jetter, J.; Masera, O.; Mehta, S.; Moss, J.; Ramanathan, V. Cleaner Cooking Solutions to Achieve Health, Climate, and Economic Co-benefits. Environ. Sci. Technol. 2013, 47, 3944-3952. [CrossRef] [PubMed]

7. Jetter, J.J.; Kariherb, P. Solid Fuel Household Cook Stoves: Characterization of Performance and Emissions. Biomass Bioenergy 2009, 33, 294-305. [CrossRef]

8. Njenga, M.; Karanja, N.; Karlsson, H.; Jamnadass, R.; Iiyama, M.; Kithinji, J.; Sundberg, C. Additional cooking fuel supply and reduced global warming potential from recycling charcoal dust into charcoal briquette in Kenya. J. Clean. Prod. 2014, 81, 81-88. [CrossRef]

9. Cundale, K.; Thomas, R.; Malava, J.K.; Havens, D.; Mortimer, K.; Conteh, L. A health intervention or a kitchen appliance? Household costs and benefits of a cleaner burning biomass-fuelled cookstove in Malawi. Soc. Sci. Med. 2017, 183, 1-10. [CrossRef] [PubMed]

10. Thakur, M.; Nuyts, P.A.; Boudewijns, E.A.; Kim, J.F.; Faber, T.; Babu, G.R.; Van Schayck, O.C.; Been, J.V. Impact of improved cookstoves on women's and child health in low and middle income countries: A systematic review and meta-analysis. Thorax 2018. [CrossRef] [PubMed]

11. LSTM Led Cooking and Pneumonia Study (CAPS). 2016. Available online: https://www.lstmed.ac.uk/newsevents/news/two-year-study-finds-no-evidence-that-cleaner-cookstoves-reduce-pneumonia-in (accessed on 29 May 2018).

12. ESMAP \& GACC. The State of the Global Clean and Improved Cooking Sector; Technical Report 007/15; Energy Sector Management Assistance Programme, The World Bank: Washington, DC, USA, 2015.

13. Stojanovski, O; Thurber, M.; Wolak, F. Rural energy access through solar home systems: Use patterns and opportunities for improvement. Energy Sustain. Dev. 2017, 37, 33-50. [CrossRef]

14. Centre for Public Impact BCG Foundation. The Solar Home Systems initiative in Bangladesh. 2017. Available online: https:/ / www.centreforpublicimpact.org/case-study/solar-home-systems-bangladesh/ (accessed on 29 May 2018).

15. Kurata, M.; Matsui, N.; Ikemoto, Y.; Tsuboi, H. Do Determinants of Adopting Solar Home Systems Differ between Households and Micro-Enterprises? Evidence from Rural Bangladesh. Renew. Energy 2018, 129, 309-316. [CrossRef]

16. Kabir, E.; Kim, K.H.; Szulejko, J.E. Social Impacts of Solar Home Systems in Rural Areas: A Case Study in Bangladesh. Energies 2017, 10, 1615. [CrossRef]

17. Batchelor, S. Solar Electric Cooking in Africa in 2020. A Synthesis of the Possibilities. DFID UK AID 2015. 2015. Available online: https:/ / assets.publishing.service.gov.uk/media/57a08975ed915d3cfd00025a/Solar_ Electric_Cooking_Synthesis_Report.pdf (accessed on 29 May 2018).

18. Ravindranath, N.H.; Ramakrishna, J. Energy options for cooking in India. Energy Policy 1997, 1, $63-75$. [CrossRef]

19. Urmee, T.; Gyamfi, S. A review of improved Cookstove technologies and programs. Renew. Sustain. Energy Rev. 2014, 33, 625-635. [CrossRef]

20. Medina, P.; Berrueta, V.; Martínez, M.; Ruiz, V.; Ruiz-Mercado, I.; Masera, O.R. Closing the gap between lab and field cookstove tests: Benefits of multi-pot and sequencing cooking tasks through controlled burning cycles. Energy Sustain. Dev. 2017, 41, 106-111. [CrossRef]

21. Coffey, E.R.; Muvandimwe, D.; Hagar, Y.; Wiedinmyer, C.; Kanyomse, E.; Piedrahita, R.; Hannigan, M.P. New emission factors and efficiencies from in-field measurements of traditional and improved cookstoves and their potential implications. Environ. Sci. Technol. 2017, 51, 12508-12517. [CrossRef] [PubMed]

22. Murakami, S.; Levine, M.D.; Yoshino, H.; Inoue, T.; Ikaga, T.; Shimoda, Y.; Miura, S.; Sera, T.; Nishio, M.; Sakamoto, Y.; et al. Energy and Carbon Emissions: Country Studies Report, Energy Consumption, Efficiency, Conservation, and Greenhouse Gas Mitigation in Japan's Building Sector; Lawrence Berkeley National Laboratory in Collaboration with Japanese Institutions; Lawrence Berkeley National Laboratory: Berkeley, CA, USA, June 2006.

23. Lean, G. Durban Climate Conference: The Bag Ladies with a Vision; Telegraph Report; 9 December 2011; Available online: https:/ / www.telegraph.co.uk/news/earth/environment/climatechange/8946254/Durban-climateconference-the-bag-ladies-with-a-vision.html (accessed on 29 May 2018). 
24. Rezig, M.; Srairi, K.; Feliachi, M.; Alloui, L. New designs systems for induction cooking devices for heating performances improving. J. Appl. Eng. Sci. Technol. 2018, 3, 91-95.

25. Mullick, S.C.; Kandpal, T.C.; Saxena, A.K. Thermal test procedure for box-type solar cookers. Sol. Energy 1987, 39, 353-360. [CrossRef]

26. Funk, P.A. Evaluating the international standard procedure for testing solar cookers and reporting performance. Sol. Energy 2000, 68, 1-7. [CrossRef]

27. Muthusivagami, R.M.; Velraj, R.; Sethumadhavan, R. Solar cookers with and without thermal storage-A review. Renew. Sustain. Energy Rev. 2010, 14, 691-701. [CrossRef]

28. Branker, K.; Pathak, M.J.M.; Pearce, J.M. A review of solar photovoltaic levelized cost of electricity. Renew. Sustain. Energy Rev. 2011, 15, 4470-4482. [CrossRef]

29. Lai, C.S.; McCulloch, M.D. Levelized cost of electricity for solar photovoltaic and electrical energy storage. Appl. Energy 2017, 190, 191-203. [CrossRef]

30. Ayeng'o, S.P.; Schirmer, T.; Kairies, K.P.; Axelsen, H.; Sauer, D.U. Comparison of off-grid power supply systems using lead-acid and lithium-ion batteries. Sol. Energy 2018, 162, 140-152. [CrossRef]

31. Ulsrud, K.; Winther, T.; Palit, D.; Rohracher, H. Village-level solar power in Africa: Accelerating access to electricity services through a socio-technical design in Kenya. Energy Res. Soc. Sci. 2015, 5, 34-44. [CrossRef]

32. Kirubi, C.; Jacobson, A.; Kammen, D.M.; Mills, A. Community-based electric micro-grids can contribute to rural development: Evidence from Kenya. World Dev. 2009, 37, 1208-1221. [CrossRef]

33. Azimoh, C.L.; Klintenberg, P.; Wallin, F.; Karlsson, B.; Mbohwa, C. Electricity for development: Mini-grid solution for rural electrification in South Africa. Energy Convers. Manag. 2016, 110, 268-277. [CrossRef]

(C) 2018 by the authors. Licensee MDPI, Basel, Switzerland. This article is an open access article distributed under the terms and conditions of the Creative Commons Attribution (CC BY) license (http:/ / creativecommons.org/licenses/by/4.0/). 